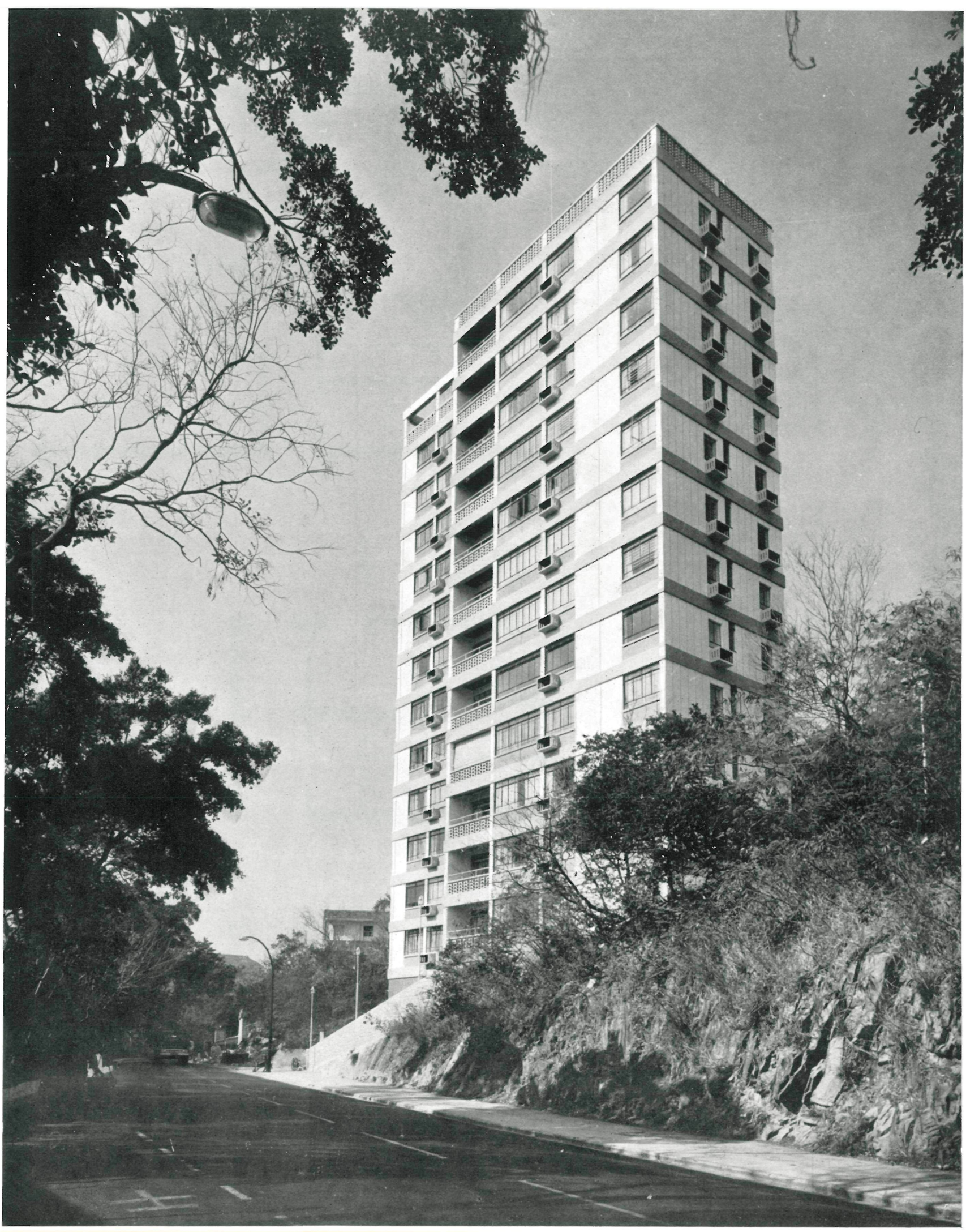

\title{
edificio de apartamentos en Hong-Kong
}

STANLEY KWOK, A.R.I.B.A., arquitecto, de la firma Eric Cumine. F.R.I.B.A.

$123-82$ 


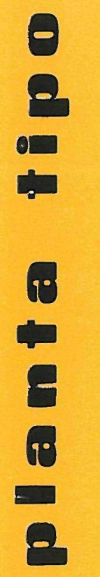

\section{simopsis}

El edificio que se describe tiene veinte plantas de al. tura y alberga dos tipos de apartamentos: uno con 166 metros cuadrados de superficie construida, y otro con 118 metros cuadrados.

Por lo que respecta a la composición estética de las fachadas, se ha conseguido una bella armonía a base de blancos $y$ grises.

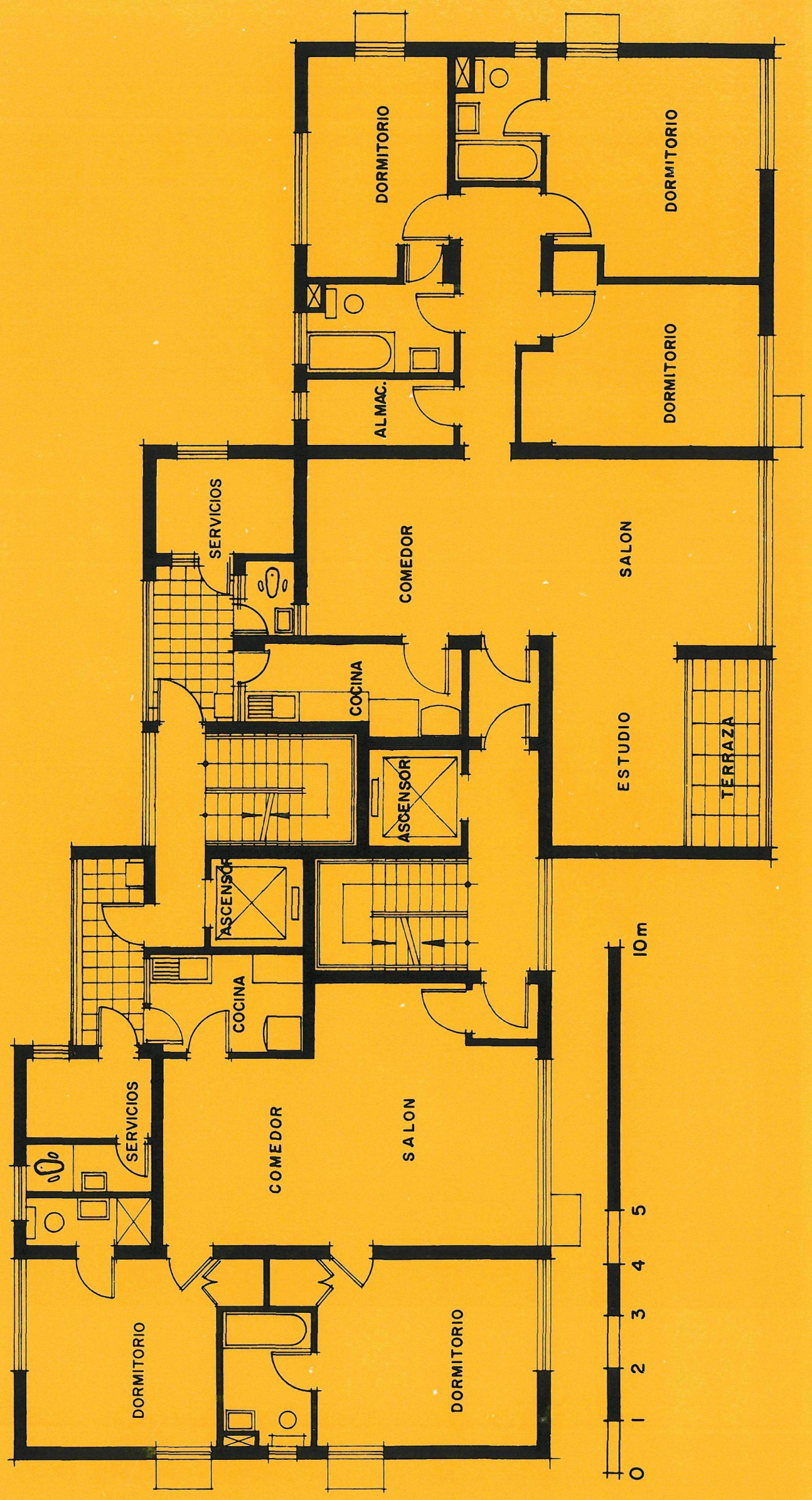



tamentos está situado sobre un emplazamiento desde el que se disfruta de una magnífica vista sobre el sector $\mathrm{O}$. de la ciudad.

Tiene veinte plantas de altura, y alberga dos tipos de apartamentos: uno de ellos, con $166 \mathrm{~m}^{2}$ de superficie construida, y otro con 118 metros cuadrados.

E1 acabado de los paramentos exteriores ha sido realiza. do utilizando blancos y grises.

La construcción se asienta sobre un zócalo revestido con estuco, de tipo granítico oscuro, que se repite en los paneles de debajo de las ventanas.
Este edificio de apar-

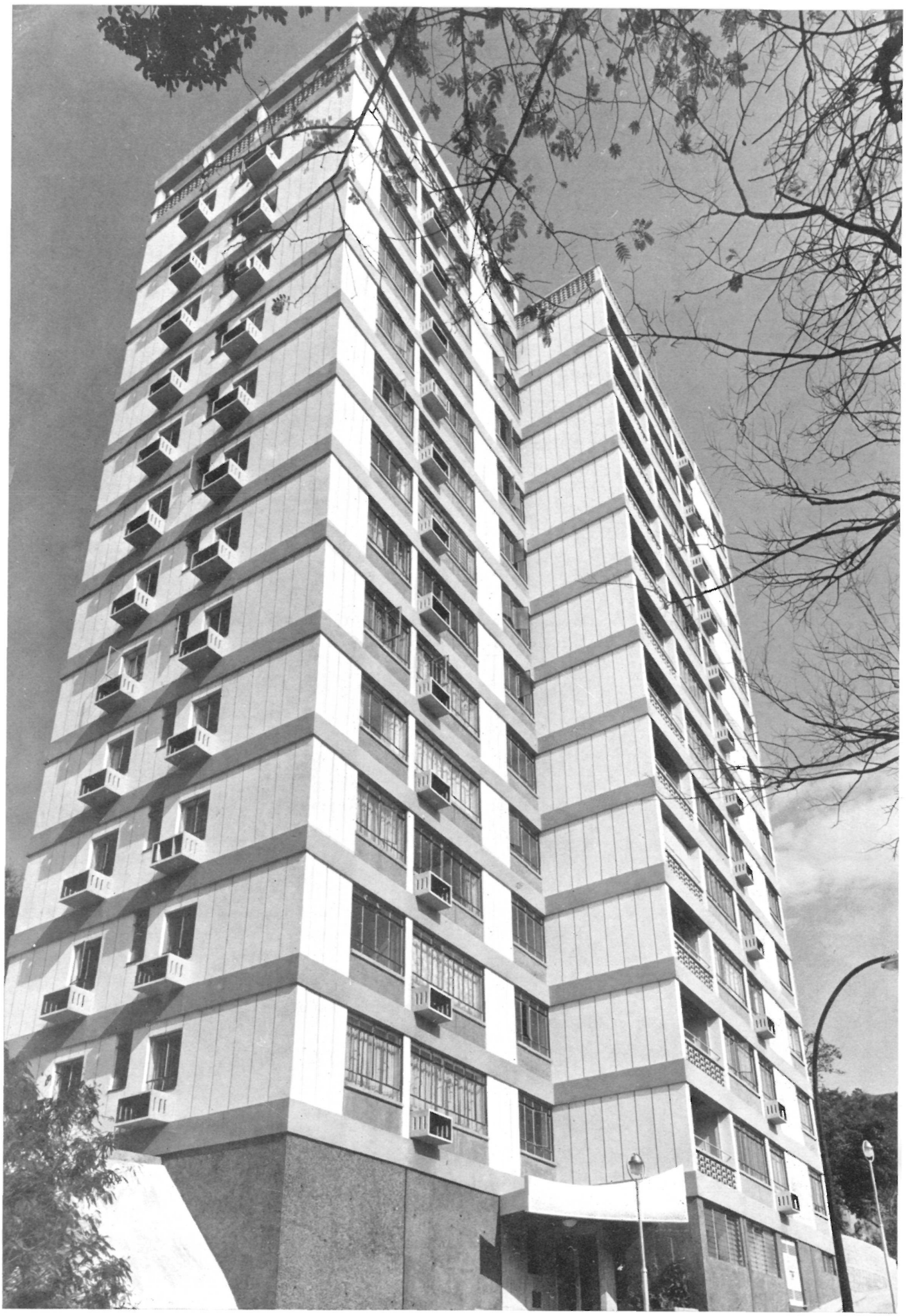

El resto de las fachadas presenta un acabado a base de estuco realizado con cemento blanco, resaltado por las impostas grises que marcan la separación de las diferentes plantas.

Una serie de cajas de cemento acusan la posición de los elementos para el acondicionamiento de aire de los dormitorios. Una celosía gris, de cemento, constituye la barandilla protectora de la terraza de la sala de estar, en los apartamentos mayores.

La entrada al inmueble se encuentra en el ángulo formado por los dos cuerpos que constituyen la planta; está recercada con travertino y dispone de bellas jardineras de granito.

El edificio es sencillo y funcional, cual corresponde a este tipo de construcciones. 


\section{Immentole de Iogements ì Homg = Kong}

Stanley Kwok, A.R.I.B.A., architecte, de Eric Cumine, F.R.I.B.A.

L'immeuble décrit ici comprend vingt étages de hauteur et abrite deux types d'appartements: l'un de $166 \mathrm{~m}^{2}$ de surface construite et l'autre de $118 \mathrm{~m}^{2}$.

En ce qui concerne la composition esthétique de ses façades, une belle harmonie a été obtenue à l'aide de blanc et de gris.

\section{Housing bolok im Hong = Komg}

Stanley Kwok, A.R.I.B.A., architect, of Eric Cumine, F.R.I.B.A.

This building has 30 storeys and contains two types of flats: one with a surface of $166 \mathrm{~m}^{2}$, and another with $118 \mathrm{~m}^{2}$ floor area.

The external elevations show an attractive black and white pattern.

\section{Wolnothaus in Hong = Kong}

Stanley Kwok, A.R.I.B.A., Architekt, von Eric Cumine, F.R.I.B.A.

Das Gebäude besitzt 20 Stockwerke und enthält 2 Arten von Appartements: Die einen umfassen $166 \mathrm{~m}^{2}$ bebaute Fläche und die anderen $118 \mathrm{~m}^{2}$.

Was den ästehthischen Anblick des Gebäudes betrifft, so hat man eine gute Harmonie auf Grund von weiss und grau erzielt. 